\section{Loyalitas Kreativitas \\ Aldi Masyarakat Kreatif}

P-ISSN 2722-2101, E-ISSN 2722-4201

Program Studi Ekonomi Manajemen Universitas Pamulang

Jurnal LOKABMAS Kreatif Vol. 01, No. 01, Hal. 21- 26

Email:jurnalkreatif.manajemen@gmail.com

\title{
PENGARUH MANAJEMEN WAKTU TERHADAP KINERJA KELOMPOK PKK DALAM PENGELOLAAN MANAJEMEN KEUANGAN DI DESA NGANGGLIK
}

\author{
Jublina Oktora, Yenny Merinatul, Vidya Amalia, Rony Heriyanto, M. Zaenal Muttaqin \\ Dosen Ekonomi Fakultas Ekonomi Universitas Pamulang

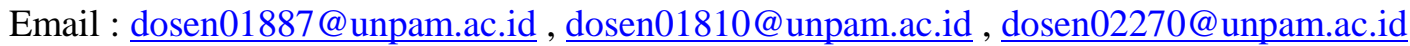
dosen01903@unpam.ac.id
\end{abstract}

\begin{abstract}
ABSTRAK
Pengabdian ini berjudul Pengaruh manajemen waktu terhadap kinerja kelompok PKK dalam pengelolaan manajemen keuangan di desa ngangglik.

Tujuan pengabdian ini adalah untuk Membantu memberikan arahan terhadap kepala keluarga, anakanak dan terutama untuk para wanita yg bergerak di bidang PKK. Manfaat manajemen waktu dan keuangan sangat baik bila dilakukan secara disiplin dan terorganisir.

Metode pelaksanaan pengabdian ini dilakukan dalam beberapa kegiatan yaitu tahap survei yaitu sosialisasi dilakukan dengan menyusun berbagai hal yang akan disampaikan pada saat kegiatan pengabdian yang akan dilakukan yang meliputi: penyusunan materi yang akan diberikan, penyusunan jadwal pemberian materi, pembagian tugas tim pengabdian dan survei ke lokasi pengabdian. Tahap sosialisasi yaitu sebelum kegiatan pengabdian dilaksanakan terlebih dahulu, dilakukan tahap sosialisasi yaitu melakukan silaturahmi dengan Bapak Lurah desa ngangglik untuk menyampaikan maksud dan tujuan pengabdian ini. Pada tahap ini juga dilakukan jalinan kerjasama dan menentukan jadwal kegiatan pengabdian. Tim pelaksana kegiatan pengabdian pada masyarakat adalah dosen Fakultas Ekonomi jurusan manajemen sebanyak 5 orang. Tim pengabdian memberikan materi tentang Pengaruh manajemen waktu terhadap kinerja kelompok PKK dalam pengelolaan manajemen keuangan di desa ngangglik dan yang memberikan pelatihan disana yaitu dosen UNPAM.

Kesimpulan dari pengabdian ini adalah Peserta kurang mengerti apa itu manajemen waktu yg dilakukan secara disiplin. Peserta juga belum mengetahui bagaimana cara menjalankan manajemen keuangan secara teratur dan efektif. Harapan kami dengan pengabdian ini dapat membuka wawasan masyarakat yang diperoleh yaitu bertambahnya keilmuan bagi para masyarakat tentang pengaruh manajemen waktu terhadap kinerja kelompok PKK dalam pengelolaan manajemen keuangan di desa ngangglik dan Ilmu yang diperoleh pada Pengabdian Masyarakat kali ini diharapkan mampu memberikan semangat baru bagi para Dosen dalam menyampaikan materi dan motivasi serta berkontribusi bagi generasi muda, baik dilingkungan sekolah, kampus dan keluarga
\end{abstract}

\section{Kata Kunci: Manajemen Waktu, Manajemen Keuangan, Kinerja PKK}

\section{ABSTRAC}

This dedication is titled The Effect Of Time Management On The Performance Of The PKK Group In Managing Financial Management In The Ngangglik Village.

The purpose of this service is to help provide direction to the head of the family, children and especially to women who are engaged in the PKK. The benefits of time and financial management are very good when done in a disciplined and organized manner.

The method of implementing this service is carried out in a number of activities, namely the survey stage, namely the socialization carried out by compiling various things to be delivered at the time of service 


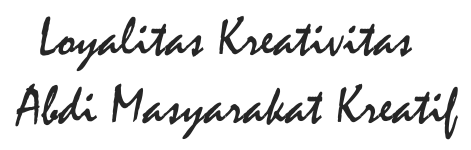

P-ISSN 2722-2101, E-ISSN 2722-4201

Program Studi Ekonomi Manajemen Universitas Pamulang

Jurnal LOKABMAS Kreatif Vol. 01, No. 01, Hal. 21- 26

Email:jurnalkreatif.manajemen@gmail.com

activities that will be carried out which include: preparation of material to be given, preparation of material delivery schedules, division of tasks of the service team and surveys to the location devotion. The socialization stage, which is prior to the community service activities being carried out, the socialization stage was carried out by making hospitality with the village chief of the ngangglik village to convey the aims and objectives of this service. At this stage also carried out the fabric of cooperation and determine the schedule of service activities. The implementation team of community service activities is a lecturer in the faculty of economics majoring in management as many as 5 people. The dedication team provided material on the effect of time management on the performance of the PKK group in managing financial management on the performance of the PKK group in managing financial management in the ngangglik village and the training there was UNPAM lecturers.

The conclusion of this dedication is that participants do not understand what time management is done in a disciplined manner. Participants also do not know how to carry out financial management regularly and effectively. Our hope with this dedication can open community insights gained namely increasing knowledge for the community about the influence of time management on the performance of the PKK group in managing financial management in the ngangglik village and the knowledge gained in community service this time is expected to be able to provide new enthusiasm for lecturers in deliver material and motivation and contribute to the younger generation, both within the school, campus and family.

\section{Keywords: Time management, Financial management, PKK performane.}

\section{PENDAHULUAN}

Hidup dalam masa yang serba canggih seperti zaman sekarang ini membuat semua orang perlu memahami adanya manajemen waktu. Dalam suatu pekerjaan, apabila seseorang mempunyai perencanaan dan pengelolaan manajemen tepat waktu tentu akan memiliki nilai yang positif dan mungkin saja akan membuat orang tersebut lebih cepat melangkah maju dibandingkan dengan yang lainnya.

Dilihat dari sisi positif maka orang tersebut bisa memiliki waktu luang yang cukup banyak karena tidak perlu lembur setiap hari sehingga beliau juga memiliki cukup waktu untuk bercengkerama dengan keluarga, sahabat ataupun kolega lainnya.

Waktu merupakan kuantitas yang dapat diukur dimulai dari detik, menit, jam, hari, bulan dan tahun. Hitungan waktu merupakan bentuk upaya untuk menertibkan kekacauan menurut National Safety Council (2003:42).

Waktu juga sumber daya yang tidak dapat dibeli atau dijual, waktu tidak dapat ditambah atau dikurangi. Setiap harinya, semua orang memiliki jumlah waktu yang sama yaitu 24 jam. Orang yang berhasil memaksimalkan waktu adalah yang menerapkan teknik dan sistem yang berbeda-beda, namun memiliki satu tujuan yang sama dan memiliki visi tentang bagaimana cara seseorang menghabiskan waktu, visi yang mengandung kesadaran tentang prioritas dan mengetahui apa yang ingin dilakukan dengan waktu yang tersedia menurut Harvard Business School (2006:4).

Menurut Marquis dan Huston (2010:114) bahwa secara periodik seseorang harus mengkaji ulang daftar perencanaan dari prioritas untuk melihat apakah ada yang tidak dilaksanakan dan mengkaji mengapa hal tersebut tidak dilaksanakan. Suatu perencanaan harus fleksibel dalam mengimplementasikan kenyataannya, langkah terakhir dalam manajemen waktu adalah memprioritaskan kembali.

Menurut Harvard Business School (2006:2) orang-orang yang efektif dalam membagi waktu dan mengalokasikan waktu untuk mengerjakan hal-hal yang paling penting, yang memberikan hasil paling besar adalah orang yang membagi waktu, memikirkan secara kritis bagaimana mereka harus menggunakan waktu mereka. Mereka memiliki rencana yang jelas dalam pikiran serta tidak menyia-nyiakan waktu. 


\section{Loyalitas Kreativitas \\ Aldi Masyarakat Kreatif}

P-ISSN 2722-2101, E-ISSN 2722-4201

Program Studi Ekonomi Manajemen Universitas Pamulang

Jurnal LOKABMAS Kreatif Vol. 01, No. 01, Hal. 21- 26

Email:jurnalkreatif.manajemen@gmail.com
Selain waktu yang di prioritaskan, masih ada bagian lain yang perlu untuk dilakukan yaitu memberikan laporan keuangan secara transparan, efektif dan efisien. Laporan keuangan yang lengkap biasanya meliputi neraca, laporan laba-rugi, laporan perubahan posisi keuangan (yang dapat disajikan dalam berbagai cara, misalnya sebagai laporan arus kas atau laporan arus dana), catatan dan laporan keuangan. Disamping itu juga termasuk informasi tambahan yang berkaitan dengan laporan tersebut, misalnya informasi keuangan segmen industri dan geografis serta pengungkapan pengaruh perubahan harga.

Laporan keuangan menurut Thahir (2008:5) merupakan hasil dari kegiatan operasi normal perusahaan akan memberikan informasi keuangan yang berguna bagi entitas-entitas di dalam perusahaan itu sendiri maupun entitasentitas lain di luar perusahaan.

Tujuan adanya laporan keuangan adalah menyediakan informasi yang menyangkut posisi keuangan, kinerja serta perubahan posisi keuangan suatu perusahaan yang bermanfaat bagi sejumlah besar pemakai dalam pengambilan keputusan ekonomi menurut Dermawan (2012:25).

Diharapkan setelah adanya penggunaan manajemen waktu dan manajemen keuangan yang baik maka akan menghasilkan kinerja yang baik, menguntungkan dalam pencapaian target perusahaan, organisasi atau individu. Sebaliknya, penerapan manajemen manajemen waktu dan manajemen keuangan secara tidak baik bisa berdampak negatif terhadap kinerja, pencapaian target dan tujuan perusahaan, organisasi atau individu

Definisi manajemen waktu adalah suatu bentuk perencanaan, mengorganisir, menggerakkan dan pengawasan terhadap produktivitas waktu. Waktu ini juga merupakan salah satu sumber daya yang harus dikelola dengan baik agar individu atau suatu organisasi bisa mencapai tujuan secara efektif dan efisien.

Setelah manajemen waktu yang dipelajari, penting juga memahami manajemen keuangan yang ada. Manajemen keuangan adalah suatu kegiatan perencanaan, penganggaran, pemeriksaan, pengelolaan, pengendalian, pencarian dan penyimpanan dana yang dimiliki oleh organisasi atau perusahaan.

Menurut Sartono (2000:3) tujuan manajemen keuangan yaitu

1. Memaksimalkan kemakmuran pemegang saham dapat ditempuh dengan memaksimalkan nilai perusahaan.

2. Secara konseptual jelas sebagai pedoman dalam pengambilan keputusan yang mempertimbangkan faktor resiko.

3. Manajemen harus mempertimbangkan kepentingan pemilik, kreditor dan pihak lain yang berkaitan dengan perusahaan.

4. Memaksimalkan kemakmuran pemegang saham lebih menekankan pada aliran kas dari pada laba bersih dalam pengertian akuntansi.

5. Tidak mengabaikan social objectives dan kewajiban sosial, seperti lingkungan eksternal, keselamatan kerja dan keamanan produk.

Manajemen waktu dan manajemen keuangan yang baik bisa mempengaruhi kinerja seseorang. Kinerja menurut A. Anwar Prabu Mangkunegara (2001:67) adalah hasil kerja secara kualitas dan kuantitas yang dicapai oleh seorang pegawai dalam melaksanakan tugasnya sesuai dengan tanggung jawab yang diberikan kepadanya.

Menurut A. Anwar Prabu Mangkunegara (2001:67), Faktor - faktor yang mempengaruhi kinerja adalah

\section{Faktor Motivasi}

Motivasi terbentuk dari sikap seorang pegawai dalam menghadapi situasi kerja. Motivasi merupakan kondisi yang menggerakkan diri pegawai yang terarah untuk mencapai tujuan organisasi. Sikap mental merupakan kondisi mental yang mendorong diri pegawai untuk berusaha mencapai prestasi kerja secara maksimal. 


\section{Loyalitas Kreativitas \\ Aldi Masyarakat Kreatif}

P-ISSN 2722-2101, E-ISSN 2722-4201

Program Studi Ekonomi Manajemen Universitas Pamulang

Jurnal LOKABMAS Kreatif Vol. 01, No. 01, Hal. 21- 26

Email:jurnalkreatif.manajemen@gmail.com
Pegawai akan mampu mencapai kinerja maksimal jika ia memiliki motivasi tinggi.

\section{Faktor Kemampuan}

Secara psikologis kemampuan pegawai terdiri dari kemampuan potensi (IQ) dan kemampuan reality (knowledge + skill). Artinya pegawai yang memiliki IQ di atas rata-rata (IQ 110 - 120) dengan pendidikan yang memadai untuk jabatannya dan terampil dalam mengerjakan pekerjaan sehari-hari, maka ia akan lebih mudah mencapai kinerja yang diharapkan. Oleh karena itu, pegawai perlu ditempatkan pada pekerjaan yang sesuai dengan keahliannya.

Berdasarkan pendapat ahli di atas, jelaslah bahwa faktor kemampuan dapat mempengaruhi kinerja karena kemampuan yang tinggi maka kinerja pegawai pun akan tercapai. Sebaliknya, bila kemampuan pegawai rendah atau tidak sesuai dengan keahliannya maka kinerja pun tidak akan tercapai. Begitu juga dengan faktor motivasi yang merupakan kondisi yang menggerakkan diri pegawai untuk berusaha mencapai prestasi kerja secara maksimal.

\section{TINJAUAN PUSTAKA}

\section{Pengertian Manajemen Keuangan}

Menurut Wikipedia Bahasa Indonesia dalam Fahmi (2011:12), manajemen keuangan adalah suatu kegiatan perencanaan, penganggaran, pemeriksaan, pengelolaan, pengendalian, pencarian dan penyimpanan dana yang dimiliki oleh organisasi atau perusahaan.

Manajemen keuangan berhubungan dengan 3 aktivitas, yaitu:

1) Aktivitas penggunaan dana yaitu aktivitas untuk menginvestasikan dana pada berbagai aktiva.

2) Aktivitas perolehan dana yaitu aktivitas untuk mendapatkan sumber dana, baik dari sumber dana internal maupun sumber dana eksternal perusahaan.

3) Aktivitas pengelolaan aktiva yaitu setelah dana diperoleh dan dialokasikan dalam bentuk aktiva harus dikelola seefisien mungkin.
Menurut Wikipedia Bahasa Indonesia dalam Fahmi (2011:13) ada 7 fungsi manajemen keuangan yaitu:

1) Perencanaan keuangan yaitu membuat rencana pemasukan dan pengeluaran serta kegiatan-kegiatan lainnya untuk periode tertentu.

2) Penganggaran keuangan yaitu tindak lanjut dari perencanaan keuangan dengan membuat detail pengeluaran dan pemasukan.

3) Pengelolaan keuangan yaitu menggunakan dana perusahaan untuk memaksimalkan dana yang ada dengan berbagai cara.

4) Pencarian keuangan yaitu mencari dan mengeksploitasi sumber dana yang ada untuk operasional kegiatan perusahaan.

5) Penyimpanan keuangan yaitu mengumpulkan dana perusahaan serta menyimpan dana tersebut dengan aman.

6) Pengendalian keuangan yaitu melakukan evaluasi serta perbaikan atas keuangan dan sistem keuangan pada perusahaan.

7) Pemeriksaan keuangan yaitu melakukan audit internal atas keuangan perusahaan yang ada

\section{Pengertian Manajemen Waktu}

Pengertian manajemen waktu menurut Forsyth (2009:10) yang menyatakan bahwa :

Manajeman waktu adalah cara bagaimana membuat waktu menjadi terkendali sehingga menjamin terciptanya sebuah efektifitas dan efisiensi juga produktivitas.

Prinsip-prinsip manajemen waktu untuk mengelola waktu dengan efisien yaitu

1) Menghargai waktu

2) Menyusun rencana atau jadwal

3) Memiliki tujuan yang jelas

4) Membuat batas waktu (deadline)

5) Memiliki kegiatan lain untuk melepaskan stres

6) Tidak bekerja secara multitasking

7) Beristirahat lebih cepat 


\section{Loyalitas Kreativitas \\ Aldi Masyarakat Kreatif}

P-ISSN 2722-2101, E-ISSN 2722-4201

Program Studi Ekonomi Manajemen Universitas Pamulang

Jurnal LOKABMAS Kreatif Vol. 01, No. 01, Hal. 21- 26

Email:jurnalkreatif.manajemen@gmail.com

Pada saat ini banyak orang yang memiliki banyak pekerjaan yang harus dilakukan dengan waktu yang sangat terbatas. Oleh karena itu, pentingnya menggunakan prinsip manajemen waktu untuk menjadi sukses di bidang pekerjaannya. Setiap prinsip itu saling memiliki keterkaitan sehingga perlu menjalankannya secara keseluruhan agar dapat membantu saat mengelola waktu dengan efisien.

\section{METODE PELAKSANAAN}

Metode pelaksanaan pengabdian ini dilakukan dalam beberapa kegiatan yaitu tahap survei yaitu sosialisasi dilakukan dengan menyusun berbagai hal yang akan disampaikan pada saat kegiatan pengabdian yang akan dilakukan yang meliputi: penyusunan materi yang akan diberikan, penyusunan jadwal pemberian materi, pembagian tugas tim pengabdian dan survei ke lokasi pengabdian. Tahap sosialisasi yaitu sebelum kegiatan pengabdian dilaksanakan terlebih dahulu dilakukan tahap sosialisasi yaitu melakukan silaturahmi dengan Bapak Lurah, menyampaikan maksud dan tujuan pengabdian ini. Pada tahap ini juga dilakukan jalinan kerjasama dan menentukan jadwal kegiatan pengabdian. Tim pelaksana kegiatan pengabdian pada masyarakat adalah dosen Fakultas Ekonomi jurusan manajemen sebanyak 5 orang. Tim pengabdian memberikan materi tentang Pengaruh manajemen waktu terhadap kinerja kelompok PKK dalam pengelolaan manajemen keuangan di desa ngangglik.

\section{HASIL DAN PEMBAHASAN}

Pengabdian Masyarakat (LPPM) Universitas Pamulang yang dilakukan oleh dosen-dosen program studi Manajemen telah berjalan dengan lancar dan mendapat sambutan hangat dari tempat pelaksanaan kegiatan ini yaitu di desa ngangglik, kota batu, malang.

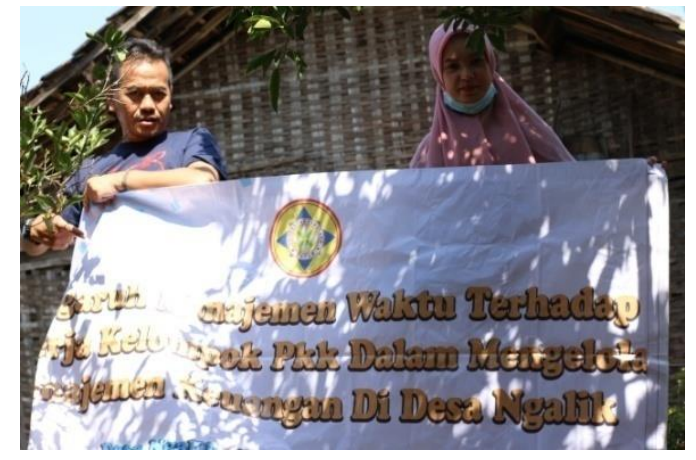

Harapan kami dengan pengabdian ini dapat membuka wawasan masyarakat yang diperoleh yaitu bertambahnya keilmuan bagi para para masyarakat desa ngangglik tentang pengaruh manajemen waktu terhadap kinerja kelompok PKK dalam pengelolaan manajemen keuangan di desa ngangglik.

\section{KESIMPULAN DAN SARAN}

\section{Kesimpulan}

Peserta kurang mengerti apa itu manajemen waktu yang diprioritaskan dan manajemen keuangan dalam bentuk laporan keuangan yang diperuntukkan agar dapat menghasilkan kinerja PKK yang baik.

\section{Saran}

Setelah pengabdian ini diharapkan peserta dapat memiliki pengetahuan dan menjalankan adanya prioritas waktu dan laporan keuangan yang baik sehingga kinerja PKK dapat berjalan dengan baik dan efektif.

\section{DAFTAR PUSTAKA}

Harvard Business School. 2006. Pocket Mentor Managing time. Jakarta : Erlangga.

Marquis \& Huston. 2010. Kepemimpinan dan Manajemen Keperawatan Teori dan Aplikasi Edisi 4. Jakarta : Penerbit Buku Kedokteran EGC.

National Safety Council. 2003. Manajemen Stres. Jakarta : EGC. 


\section{Loyalitas Kreativitas \\ Aldi Masyarakat Kreatif}

P-ISSN 2722-2101, E-ISSN 2722-4201

Program Studi Ekonomi Manajemen Universitas Pamulang Jurnal LOKABMAS Kreatif Vol. 01, No. 01, Hal. 21- 26

Email:jurnalkreatif.manajemen@gmail.com

Uhar Suharsaputra. 2013. Administrasi

Pendidikan. Bandung : PT. Refika Aditama.

Pasaribu, V. L. D., Agrasadya, A., Shabrina, N., \& Krisnaldy, K. (2020). MENJADI

ENTERPRENEUR MUDA YANG MEMILIKI

JIWA LEADERSHIP UNTUK

MENGHADAPI MASA DEPAN. Abdi

Laksana, 1(1)

Pasaribu, V. L. D., Elburdah, R. P., Sudarso, E., \& Fauziah, G. (2020). PENGGUNAAN MANAJEMEN WAKTU TERHADAP PENINGKATAN PRESTASI BELAJAR DI

SMP ARAISIYAH. Jurnal ABDIMAS, 1(1)

Pasaribu, V. L. D., Susanti, F., \& Hartuti, E. T. K. (2019). MEMOTIVASI SISWA DAN SISWI SMK LETRIS INDONESIA DI DALAM MENENTUKAN PILIHAN UNTUK MELANJUTKAN PENDIDIKAN ATAU BEKERJA SETELAH LULUS

SEKOLAH. Jurnal Pengabdian Dharma Laksana, 1(2), 161-172.

\section{DOKUMENTASIFOTO KEGIATAN}
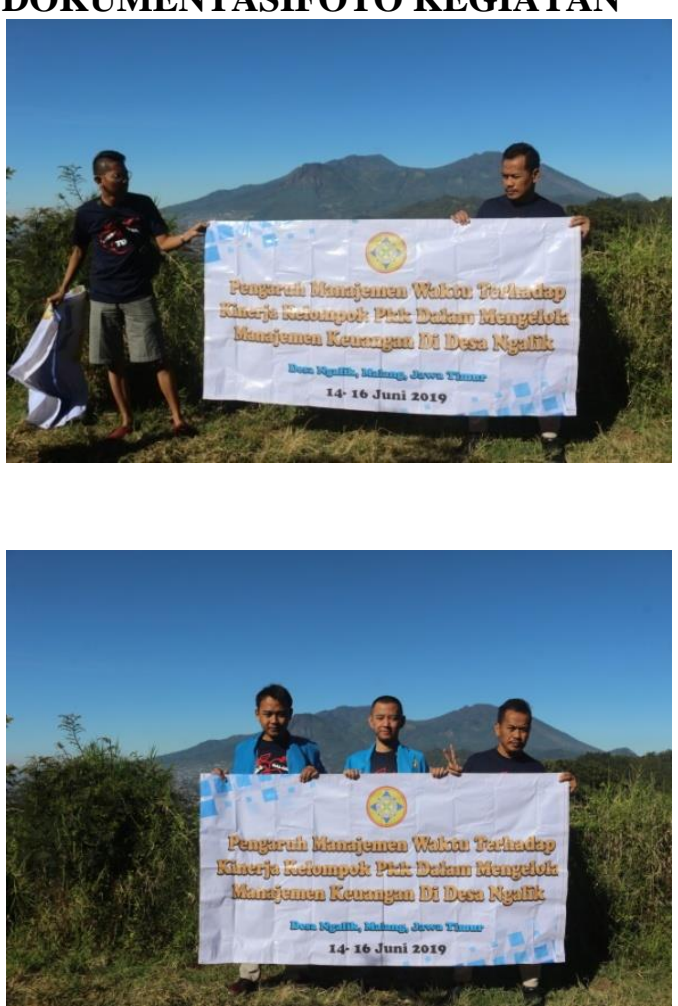